\title{
ADVANCEMENTS IN TELE-ROBOTIC PIPELAYING
}

\author{
Leonhard E. Bernold, \\ Associate Professor \\ Bin Li, Intern. Scholar \\ Construction Automation Robotics Laboratory (CARL.ce.ncsu.edu), \\ North Carolina State University, Raleigh, NC 27511
}

\begin{abstract}
The labor intensive construction industry has a very high accident rate. One of the key reasons for this is the exposure of workers to a hazardous environment such as heights, confined narrow spaces, and exposure to health threatening fumes, dust, and noise. Tele-robotic operation, which allows an operator to control a mechanical tool from a safe distance, provides a technical alternative. Because of the need to be competitive on every project-bid, contractors have to be assured that new technologies not only work in the rugged environment of a construction site but that they also reduce cost. This paper will present an example of such a technology, a pipe manipulator that allows the remote installation of large concrete pipes in deep trenches. A second prototype has been built and successfully field-tested. The comparative evaluation of the new technology shows that it is not only safer but also more economical to use. With the goal to further improve agility, flexibility, and ease of operation, a third prototype has been readied for further field tests
\end{abstract}

Keywords: tele-robotics, safety, trenching, remote control, pipe-laying, trench collapse

\section{Introduction}

According to the Bureau of Labor Statistics (1999), in 1997 there were 1,137 deaths in the construction industry. This number equals $18 \%$ of the total fatalities from all industries and indicates that construction has the highest number of fatalities. Another source shows that the construction industry employed approximately $5 \%$ of the industrial work force, but generally accounted for nearly $20 \%$ of all accidental deaths (National Safety Council, 1997). An analysis by the National Institute for Occupational Safety and Health (NIOSH) of workers' compensation claims for 19761981 shows that excavation cave-ins were the cause of about 1,000 work-related injuries each year. Of these injuries, 140 resulted in permanent disability and 75 in death.

The traditional ways to prevent collapse and make working in a trench safe are (1) providing physical supports for each side of the trench using shoring or a trench box, or (2) sloping the sides to a safe angle.

OSHA's excavation standard requires employers to provide sloping (or benching), shoring, or shielding to protect employees in excavations 5 feet or more in depth. The only exception is for a trench dug in stable rock, where there is no loose soil or likelihood of a cave-in. Excavations less than 5 feet deep need not be protected unless a competent person has determined there is a cave-in hazard. As shown in Figure 1, depositing spoil right next to the trench make even a 5 feet deep trench a death trap. Because of the complex nature of digging soil, accidents still occur. One way to eliminate the risk, is to introduce a technical intervention such as teleoperated pipe manipulator able to lay pipe without a human in the trench. However, in order to be a viable economic alternative to the traditional methods, such technology needs to be cost effective as well. 


\section{Prototyping a Technical Intervention}

A first device able to handle large concrete pipes remotely was designed and fabricated in 1994. This first-generation pipe manipulator (PipeMan), shown in Figure 2, was subsequently improved by adding a laser and video system in order for an operator to control the entire device remotely (Lee at al., 1999). Figure 3 presents the overall architecture of the 2 generation PipeMan.

\section{Mechanical Components of PipeMan}

The actuation system consists of the following five functions:

1) H. Actuator (A_Rot1): A hydraulic actuator provides the limited \pm 100 degrees rotation of the pipe in order to line up the pipe.

2) H. Actuator (A_Rot2): A hydraulic actuator provides a locking mechanism on the back of the manipulator to prevent it from slipping off the bucket.

3) H. Cylinder (C_Trans): A hydraulic cylinder provides a linear activation of the pipe to joint the new pipe to the pipe already laid.

4) H. Bladders (B Clamp): Hydraulic bladders provide an inflating and deflating mechanism to clamp the manipulator to the bucket.

5) E. Winch (W_Hold): An electric winch is used to attach the pipe with a quick release.

Man-Machine Interface

The man-machine interface includes manipulation and visualization functions. Two microvideo cameras allow the operator to have a real-time view during final alignment of the pipe joint. One video camera covers the front of the pipe for jointing and the other faces the laser targets to monitor the laser beam for alignment.

In order the provide the operator a convenient and safe method for operating the manipulator a separate control box, shown in Figure 4, was designed and fabricated. The control box included a $\mathrm{DC} / \mathrm{DC}$ converter in order to distribute $24 \mathrm{VDC}$ to $5,9,12$, and 24 VDC as outputs. The power source to be used is $24 \mathrm{VDC}$ from the excavator. A switchstick control is added for the remote operator's easy control of the manipulator. The control box also includes three three-way switches, and one main power on/off switch. Switchstick \#1 controls rotational actuation of the hydraulic actuator (A_Rot1). Switchstick \#2 is linked to the translational actuation of the hydraulic cylinder (C_Trans). Separate three-way switches control the actuation of the hydraulic cylinder (A_Rot2), clamping actuation of the bladders (B_Clamp), and locking/unlocking of backstop (A_Rot2). The LEDs (light-emitting diodes) are used as a fault detection system. As long as an electric signal or power is applied, the LED light remains on. The hydraulic fluid for the 4 different actuation units (two actuators, one cylinder, and two bladders) is provided by a hydraulic manifold mounted on to the PipeMan.

\section{Comparative Field Tests}

As mentioned earlier, only field tests with experienced laborers and operators will show if the innovations works effectively and economically. For this purpose a comparative field test was conducted on the job-site of East Park Industrial Subdivision in Raleigh, NC. The comparative experiment included two different ways of laying the pipes: 1) traditional method, and 2) manipulator utilization. Site conditions including soil, trench width and depth, pipes, crew members, weather were the same except for a way of performing pipe laying.

The crew members laid concrete pipes the way they normally do one day, and the manipulator was utilized to do the same tasks the next day. Figure 5 presents the two methods. The soil condition of the job site was sandy clay and the concrete pipes were 36 -inch $(0.9 \mathrm{~m})$ diameter and 8 feet $(2.4 \mathrm{~m})$ long. Figure $5 \mathrm{~b}$ ) depicts the operator lining 
up a new pipe by adjusting direction and grade of the pipe using the laser as a guide.

\section{Qualitative Assessment}

The technical performance of the new system was assessed in terms of: 1) Overall performance, 2) learning curve effect, 3) acceptance and adoption, and 4) technical problems.

\section{Overall Performance}

Using both, his own laser and the laservideo targets, the operator immediately felt comfortable with the necessary adjustments and the accuracy of the installed pipes. The availability of an image showing a close-up of the pipe joint was praised and felt to be a special asset when laying pipes into deeper trenches.

\section{Learning Curve}

The workers became familiar with the new process after only a few repetitions. They laid the last 2 pieces of pipes at a consistent shorter time than the first 3 cycles.

Acceptance and Adoption

The operator, pipe-layers, and helpers accepted the new technology wholeheartedly.

\section{Technical Problems}

Although a brand-new winch was used, the weight of the large pipe used by the contractor was too much for the its baseplate. The test made clear that having two winches might be necessary. Another issue was the size of the bucket which made the backstop unworkable. A chain provided the perfect alternative solution. The inflatable bags were also not performing as expected.

\section{Cost Comparison}

The main cost items consist of: a) excavation and bedding, b) pipe laying, c) pipe manipulator rental, d) backfill \& compaction, and e) insurance. Volume of excavation for the traditional method, $21 \mathrm{~m}^{3}$, includes the benches as shown in Figure 5 while the volume for the alternative method, $11.6 \mathrm{~m}^{3}$, is based on vertical trench walls with a minimal width as required for proper haunching. As expected, the resulting cost saving, $\$ 7.52 / \mathrm{m}$ or $54 \%$, is significant.

Overall, the total cost for the excavation and laying of 36 inch $(0.9 \mathrm{~m})$ concrete pipes into a 6 feet $(1.8 \mathrm{~m})$ deep trench during the field tests are $\$ 53.7$ per meter $(\$ 16.37 / \mathrm{ft})$ for the traditional method and \$ 65.54 per meter $(\$ 20 / \mathrm{ft})$ for the observed tele-robotic method. As was anticipated, the tele-robotic option turns out to be more expensive mostly as a result of the higher cycle time, the result of the broken winch. However, simple improvements should undoubtedly result in reducing the time for laying one pipe.

\section{Third Generation PipeMan}

Based on the encouraging results of the field test, it was felt that the basic concept of PipeMan was solid. One main problem, however, was the weaknesses of the winch. A second issue was the inability of adjusting the grade without the bucket. This capability would allow an excavator to be positioned on the side of the trench. The following section will present an alternative method of holding the pipe.

\section{A Two Pronged Carriage}

The flexibility of the system design allowed us to consider exchanging the carriage holding the winch while keeping the base, holding all the controls. It was decided to fabricate an alternative to the original carriage that was based on the flexibility provided by prongs. Figure 6 presents the new design. As indicated, the pipe will be lifted simply by inserting the prongs into the pipe. A mechanical stop-plate is automatically engaged when the weight of the pipe is taken over by the prongs. This stops the pipe from sliding off.

\section{Adding a Third Degree of Freedom}

One weakness of PipeMan was the fact that it could only be used in the axis of the trench since the slope of the pipe had be adjusted 
using the bucket. In order to allow a backhoe to lay pipes from the side of the trench, a degree of freedom had to be added. Figure 7 indicates that this was accomplished by allowing the prongs to rotate at one while actuating the other end with the help of a hydraulic cylinder.

\section{$\underline{\text { Summary }}$}

Traditional trenching and pipe laying requires workers to enter the trench, resulting in many fatalities due to the nature of the soil in the trench walls and other work related circumstances. The telerobotic concept promises to drastically reduce the risk to human life by keeping the worker outside of the trench. This paper presented the major components and functions of the newest version of the teleoperated pipe manipulator that has been designed and fabricated to handle pipes that use o-ring connection. The new technology proved its technical feasibility by laying 8 piece of concrete pipes without any workers in the trench. The field test highlighted too that with the help of technical modifications, the system would also be cost effective. These modifications have been implemented to create the third generation PipeMan.

\section{Acknowledgments}

Funding for the work has been provided by Public Health Service-National Institutes of Health under contract 5 R01 CCR41305102 and 1R01 0H04201-01. Its content is solely the responsibility of the writers and do not necessarily represent the official views of NIH.

\section{$\underline{\text { References }}$}

Lee, J., Lorenc, S.J., and Bernold, L.E. (1999). "Saving Lives and Money with Robotic Trenching and Pipe Installation," ASCE Journal of Aerospace Engineering, Vol. 12, No. 2, ISSN 0893-1321, April 1999, pp. 43-49.
U.S. Department of Labor, Occupational Safety and Health Administration, Title 29 of the Code of Federal Regulations (CFR) Part 1926.650-652.

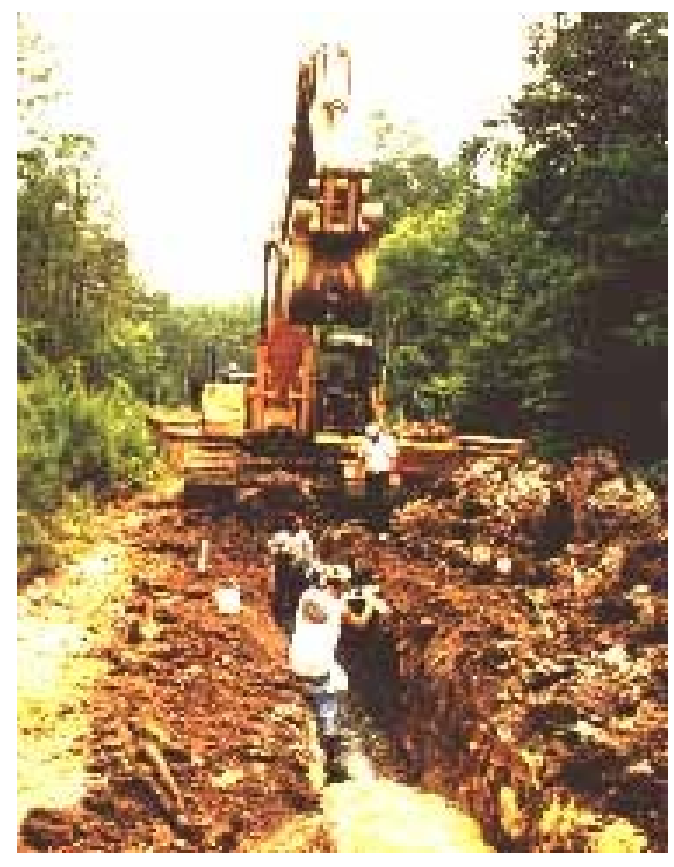

Fig 1. Dangerous Work Laying Pipes in an Open Trench
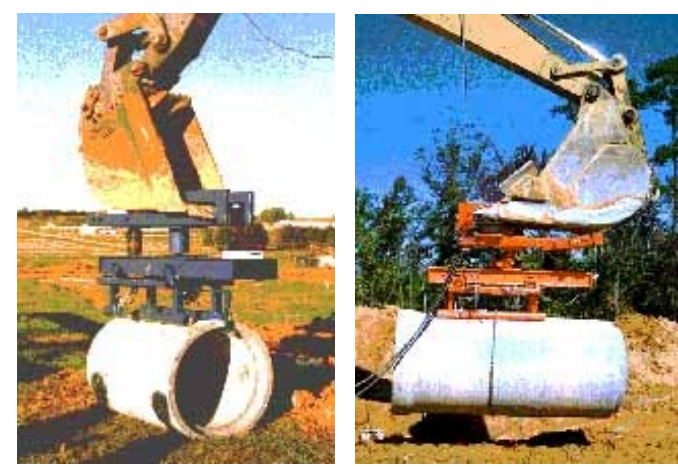

Fig 2. PipeMan Generations 1 and 2 


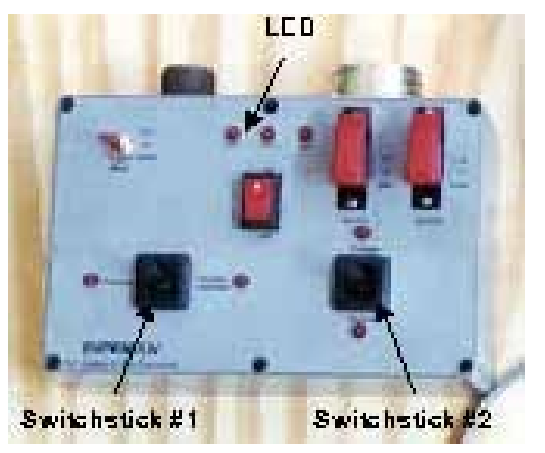

Fig. 4 Control Box for Operator

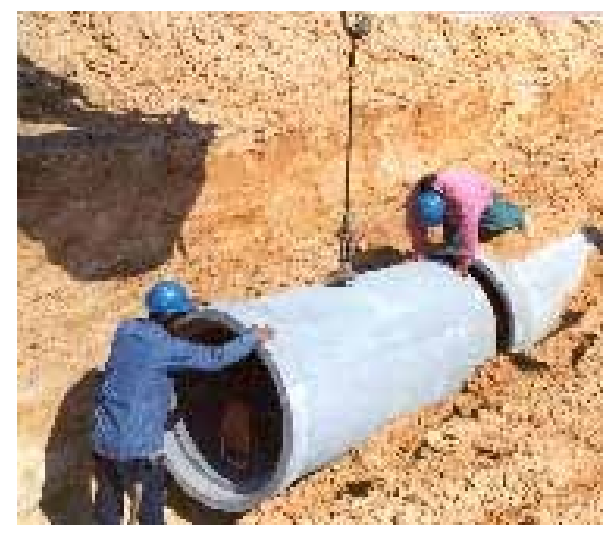

a) Laying Pipe Traditionally

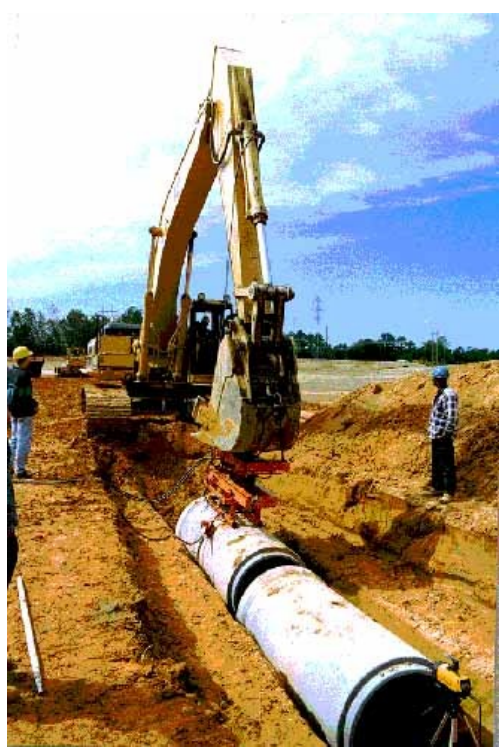

b) Laying Pipe with PipeMan

c)

Fig 5. Comparative Field Test

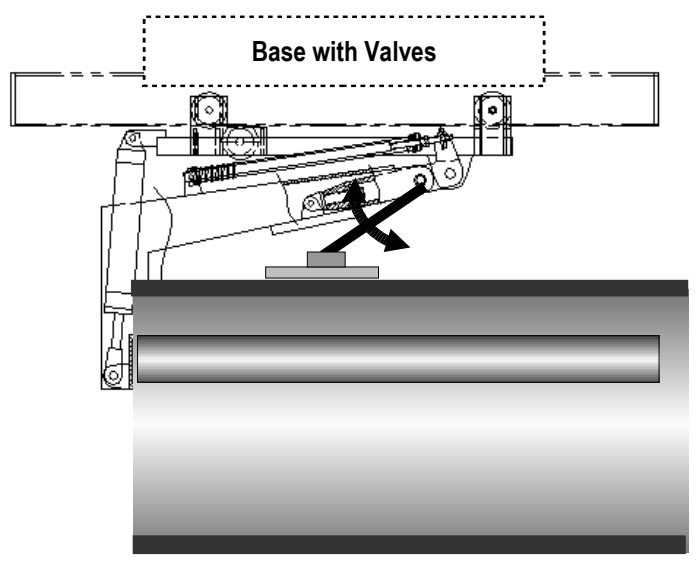

a) Side View with Loaded Pipe

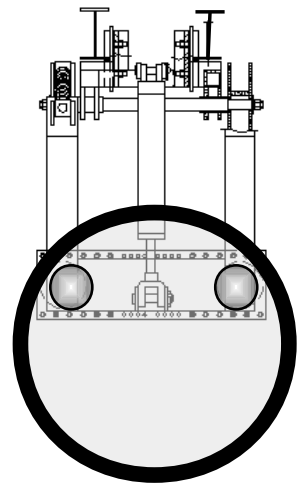

b) Front View with Loaded Pipe

Fig. 6. Pipe Carriage With Prongs

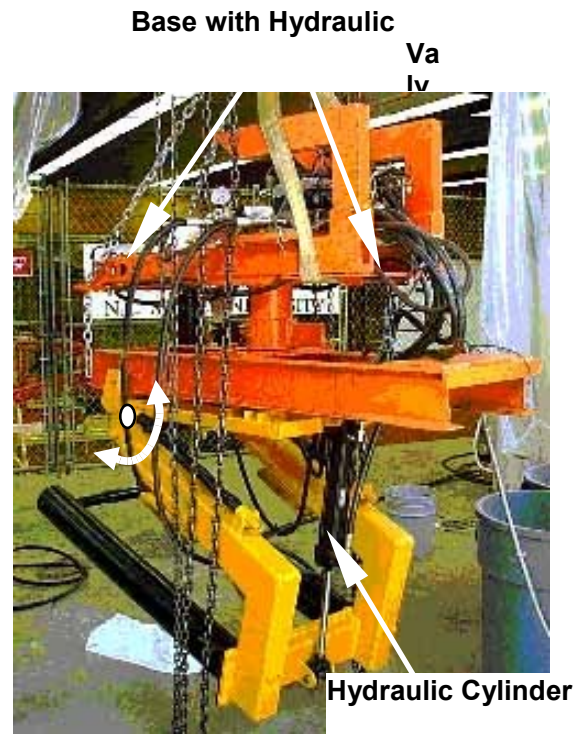

Fig 7. Third Degree of Freedom 


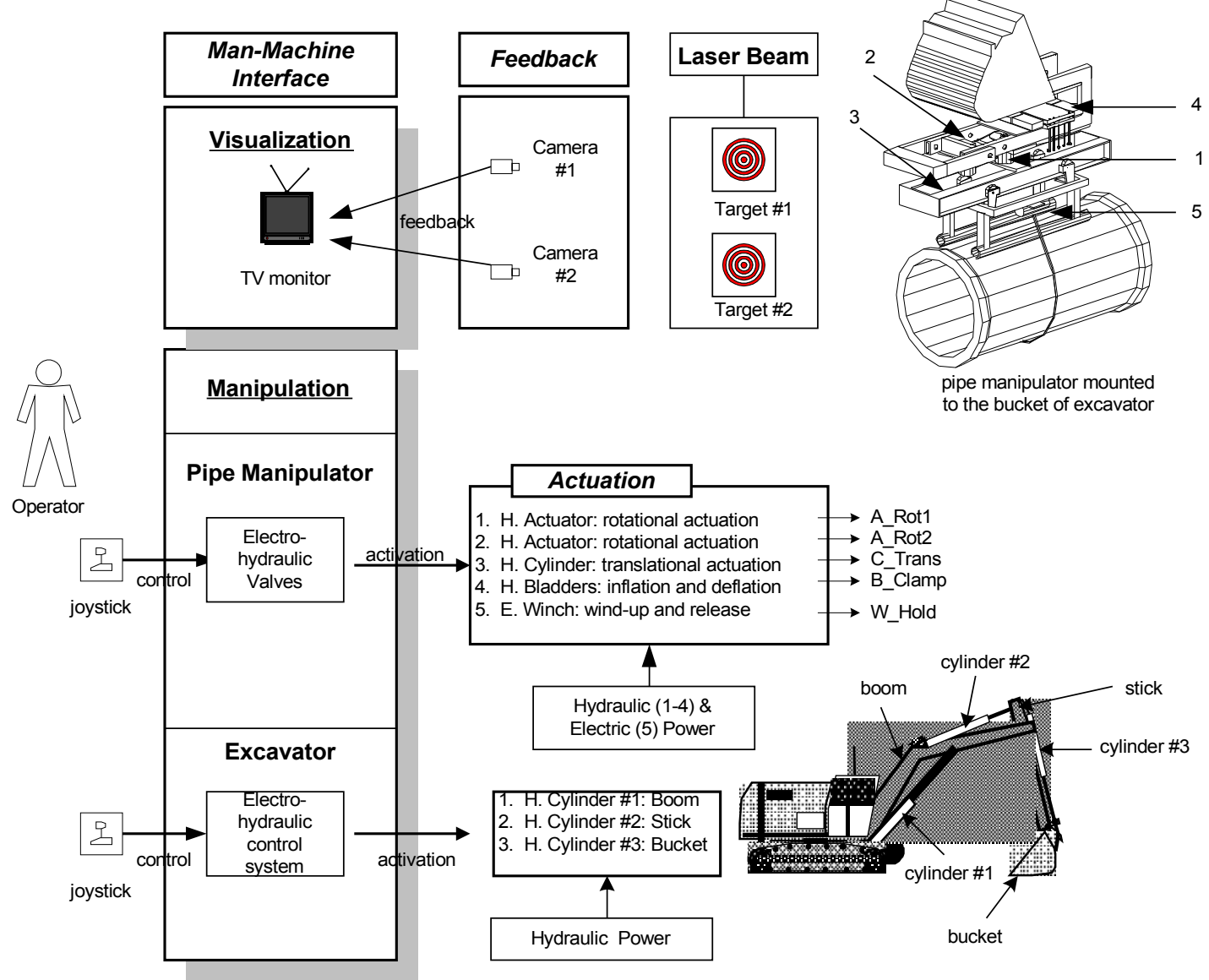

Fig 3. Layout of PipeMan Attachment 
- 7 - 